\title{
Self-rated health and venous thromboembolism among middle-aged women: a population-based cohort study
}

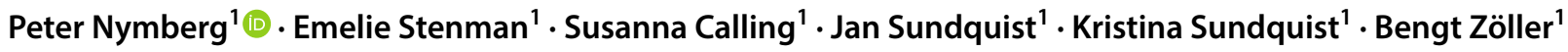

Published online: 19 November 2019

(c) The Author(s) 2019

\begin{abstract}
Venous thromboembolism (VTE) is one of the most common types of cardiovascular diseases (CVDs) and is associated with increased mortality-risk. Poor-self rated health (SHR) has been associated with elevated inflammatory markers and CVDs. However, little is known about as a predictor of incident VTE. To examine the association between self-rated health, lifestyle and incident VTE among middle-aged women. 6917 women aged 50-64 years, followed for 20 years in the Women's Health In the Lund Area (WHILA) study. After exclusion of those who medicated with anticoagulants, were living in nursing homes or suffered from cancer, stroke, VTE or CHD before baseline, a cohort of 5626 women remained. Cox regression was used to analyse the relationship between self-rated health and time to VTE, censored for any of the previous mentioned diseases during follow-up. Data were collected by questionnaires, physical examinations and Swedish registers. In total, 220 women were affected by VTE corresponding to an incidence rate of 3.9 per 1000 person-years. Adjustment for self-rated health did not significantly predict incident VTE, and neither did any of the lifestyle-related habits (e.g. physical activity and dietary habits including alcohol consumption), besides smoking. This study supports previous results with varicose veins and waist circumference as strong predictors of VTE. Poor self-rated health does not seem to be a valid predictor of VTE. Among lifestyle-related parameters, smoking was significantly associated with risk of VTE. We could also confirm the effect of the other already known risk factors.
\end{abstract}

Keywords Venous thromboembolism $\cdot$ Varicose veins $\cdot$ Prevention $\cdot$ Self-rated health $\cdot$ Women

\section{Highlights}

- Poor self-rated health does not seem to be useful as a predictor of VTE.

- Varicose veins, smoking and waist circumference showed a association with risk of incident VTE.

- Other lifestyle associated behaviors do not seem to have any strong effect on risk of incident VTE.

- Prevention in those with varicose veins can be important.

Electronic supplementary material The online version of this article (https://doi.org/10.1007/s11239-019-01995-7) contains supplementary material, which is available to authorized users.

Peter Nymberg

peter.nymberg@med.lu.se

1 Region Skåne, Center for Primary Health Care Research, Jan Waldenströms gata 35, Skåne University Hospital Malmö, University Hospital, Lund University, Jan Waldenströms gata 35, 20502 Malmö, Sweden

\section{Introduction}

The incidence of venous thromboembolism (VTE) exceeds 1 per 1000 persons-years. More than 200,000 new cases of VTE occur in the United States each year, with a corresponding mortality rate of about $30 \%$ within 30 days [1]. Among the survivors, 30\% develop recurrent VTE [1] and there is an increased mortality risk up to 8 years after the first thrombosis, [1, 2]. Provoked VTE occurs in relation to identifiable risk factors, such as pregnancy, bone fractures, or surgery [1,3]. Unprovoked VTE shares some known risk factors with other cardiovascular diseases (CVDs) such as obesity, smoking [4-7] and sleep-apnoea [8-10]. Other risk factors for VTE include high body height [11] and varicose veins [1, 12-15]. Varicose veins and VTE has been suggested to share familial susceptibility [16] and a genetic component of the familial clustering has been found for VTE, which makes heredity a potent risk factor $[17,18]$ The risk of VTE also increases with age, especially among men aged $>50$ years $[19,20]$. 
Poor self-rated health (SRH) has been associated with elevated serum inflammatory markers [21] and has also been shown to be a predictor of depression [22], stroke [23] and other CVDs [24], diabetes [25], lung-cancer [26] and allcause mortality [27, 28]. Thus, SRH is usually considered a valid and efficient measure of mental and physical health, especially in women [29], although there is still a need to identify the validity limits of SRH for prediction of illness and mortality [30].

A previous study investigating associations between the first VTE-episode and work-related disability showed a reduced risk for VTE when adjusted for good SRH. The authors discussed a possible association between low SRH and an elevated risk of incident VTE [31].

To the authors' knowledge, there are no previously published studies regarding the longitudinal association between SRH and incident VTE later in life among middle aged women. If such an association exists, it can be useful to include in risk assessment for incident VTE. In addition, as women often are more affected by poor SRH, they are particularly suitable for a study of a possible longitudinal association with VTE. SRH is also better at predicting somatic diseases in women than in men [29].

The main aim of this cohort study was to examine the association between baseline SRH in middle-aged women (50-64 years) and incident VTE. The second aim was to analyze the association between lifestyle habits, i.e. physical activity, diet, smoking, alcohol consumption and VTE.

\section{Method}

\section{Study population}

The Women's Health In the Lund Area (WHILA) is a prospective cohort study in southern Sweden. Sample characteristics, data collection and clinical definitions for WHILA have been described previously [32]. Briefly, the study invited all women $(n=10,766)$ living in any of the five municipalities around the city of Lund by December 1995, and who were born between December 1935 and December 1945 , to a screening procedure that took place from December 1995 until February 2000. A total of 6917 women consented to participate in the study, of which 6916 had complete datasets. The study population was identified through a population registry that comprised all inhabitants. A health-screening program included laboratory examinations, blood samples and a basic baseline questionnaire that was mailed along with the invitation and collected in conjunction with the first examination. The baseline questionnaire included 104 questions concerning education, household, working status, perimenopausal status, medical history, drug treatment, personal and family history of diabetes or cardiovascular disease (myocardial infarction, stroke, deep venous thrombosis or hypertension in parents or siblings with an event before the age of 60 years). It also contained questions about habits like smoking, alcohol consumption, physical activity, general dietary habits, quality of life, as well as subjective physical and mental symptoms. This questionnaire was a composite of several pre-existing and validated questionnaires.

\section{Measurements and definitions}

Information about diseases and medication was obtained from the Swedish Hospital Discharge Register, the Hospital Outpatient Register and the Swedish Cancer Register in addition to self-reported data from WHILA study baseline questionnaires and measurements. The definition of VTE includes the following ICD-codes; ICD-7; 463-466, 583.00 334.40, 334,50 682, 684. ICD-8 321, 450-453, 671 (not 671,00) 673,9. ICD-9; 437G, 451-453, 415B, 416 W, 671C, D, E, F, X, 673C, 639G. ICD-10; I26, I636, I676, I80-82, O222-225, O229, O870-873, O879, O882, O082, O087. We excluded from our analyses participants with stroke (ICD-7; 331, 332, 334.09. ICD-8; 430-434, 436. ICD-9; 430-434, 436. ICD-10; I60-I64 (not I63.6).) or CVD (ICD-7; 420. ICD-8; 410-414. ICD-9; 410-414. ICD-10; I20-I25.), cancer (ICD-7; 140-209) or VTE before baseline, both selfreported and by register. In addition, we excluded women who were living in nursing homes or similar at baseline or medicated with warfarin, dicumarol, or antithrombin (ATCcode; B01AA03, B01AA01, and B01AB02). After exclusion, 5626 women remained (Table 1).

SRH was assessed only at baseline from a single question, in which the participants were asked to rate their perceived health in a 7 -graded Likert scale from "Very poor" to "Excellent, could not be better" $(1=$ very poor, $7=$ Excellent). In this study, we classified alternative $1-4$ as poor SRH and 5-7 as good SRH. Weight and height were rounded off to the nearest $0.1 \mathrm{~kg}$ and $0.5 \mathrm{~cm}$. Body mass index (BMI) was calculated as weight in kilograms divided by height in

Table 1 Number of exclusions and reason for exclusion both by register and self-reported

Total included 6916

No. of living in nursing homes or similar 190

No. of prevalent VTE diagnoses $\quad 321$

No. of prevalent CHD 104

No. of prevalent stroke $\quad 79$

No. of prevalent cancer $\quad 716$

No. of anticoagulant (not ASA) 30

Remaining after exclusion $\quad 5626$

The same person can occur in several groups 
meters squared $\left(\mathrm{kg} / \mathrm{m}^{2}\right)$. BMI was considered as underweight if BMI was $<18.5$, normal weight if BMI $=18.5-24.9$, overweight if $\mathrm{BMI}=25.0-29.9$, obese class $\mathrm{I}$ if $\mathrm{BMI}=30.0-34.9$, obese class II if BMI $=35.0-39.9$ and obese class III if BMI was $>39.9$. BMI class II and class III were put together due to small groups. Subjects were categorized as current smokers (i.e. those who smoked regularly or occasionally) or non-smokers (i.e. former smokers and never smokers). Low physical activity, i.e. less than 30 min vigorous activity 5 days a week [33] was defined as the lower tertile among the answering alternatives (i.e. very low and low) (Table 2).

Diet was defined by questions about intake of fat, sugar, fruit or dietary fiber. If high intake of sugar or fat or low intake of dietary fiber or fruit were reported, we considered the diet as less healthy [32]. If low intake of sugar and fat and high intake of fruit and dietary fiber was reported, we considered the diet as healthy. Education was categorized into three classes; comprehensive school (9 years), upper secondary school (12 years), and university degree. In the multivariate models model, we used waist circumference instead of BMI; this was due to previous studies showing waist circumference as a valid predictor for VTE [34].

\section{Statistical analysis}

P-values were calculated with two-sided Student's $t$ test for continuous variables and with $\chi^{2}$-test for dichotomized variables. Cox proportional hazards regression was used to analyze the relationship between SRH and time to VTE. Hazard ratios (HR) with 95\% confidence intervals (CI) were calculated. Those who were diagnosed with hypertension or varicose veins after baseline were censored, as well as those who were affected by stroke, CHD or cancer diagnosis before the VTE during the follow-up time. In the multivariate model, only confounding variables that showed a significantly increased incident VTE-risk in the univariate test were included. In the first model, we adjusted for age. In the second model, we added physical activity, smoking, and waist circumference. In the third model, we completed with varicose veins and hypertension. The proportional hazard assumption was tested with Schoenfeld residuals [35, 36]. Analyses were performed in STATA 14.1.
To test the robustness of the results, we investigated the cohort in different ways, at first without excluding prevalent disease (VTE, CHD, stroke, cancer) before baseline. At the next step, we excluded all the patients both prevalent (VTE, CHD, stroke, cancer) and censured incident (CHD, stroke cancer) before VTE. We got almost the same result regardless of which we excluded, there were only small differences in hazard ratios and levels of significance. When the proportional hazard assumption test was significant in the two first models thus meaning the effect were not constant and changed over the follow-up time. We investigated the material by breaking it up into shorter time span of 5 years $(0-5$, $5-10,10-15,15-20)$. All the different time spans showed proportionality except for the time span 0-5 years. When excluding only the $0-5$ year to get broader time span, there was proportionality in all models between 5 and 20 years follow up.

\section{Results}

During a follow-up time of 20.4 years, a total of 220 women were affected by VTE. The sum of the follow-up time was $85,645.836$ years corresponding to a VTE incidence rate of 3.9 (95\% CI 2.26-2.94) per 1000 person-years. There appeared to be statistically significant differences between women that were affected by incident VTE versus women that were not affected, i.e. differences in weight, height, waist-hip ratio, smoking, high and low activity level, dietary fiber, overall diet, SRH and varicose veins.

Women with incident VTE were on average taller, heavier and had a greater waist-hip ratio than those without incident VTE. There was a higher percentage of smokers and women with a low physical active level in the group with incident VTE. Regarding diet, there were only significant differences between the groups in dietary fiber intake and overall diet. Among women with incident VTE, a higher percentage had a low intake of dietary fiber and a less healthy overall diet. In the incident VTE-group there was also a greater number with varicose veins. The SRH differed significantly between the groups with a higher percentage rating their health as poor in the incident VTE

Table 2 Definition of activity groups

\begin{tabular}{ll}
\hline Very-high & Hard training several times per week \\
High & $>3 \mathrm{~h}$ of running, skiing swimming \\
Middle-high & $1-2 \mathrm{~h} /$ week with running, swimming, gymnastics, $4 \mathrm{~h}$ light physical activity/week and total \\
& responsibility of household tasks \\
Middle & Light activity $2-4 \mathrm{~h} /$ week walking, gardening dancing. Head of responsibility of household tasks \\
Low & Mostly sitting, light household work or gardening but not head of responsibility of the tasks \\
Very low & Hardly any physical activity at all
\end{tabular}


Table 3 Univariate Cox regression with those variables which differed with a statistical significance in the baseline characteristics

\begin{tabular}{|c|c|c|c|c|c|}
\hline & Hazard ratio & $95 \% \mathrm{CI}$ & $\mathrm{p}$ & $\mathrm{n}$ & Failures \\
\hline Age & 1.05 & $1.00-1.10$ & .033 & 5626 & 220 \\
\hline Marital & & & & 5606 & 220 \\
\hline Unmarried & 1.22 & $.75-1.99$ & .42 & & \\
\hline Married & Ref & & & & \\
\hline Divorced & .99 & $.68-1.44$ & .961 & & \\
\hline Widowed & 1.10 & $.60-2.03$ & .757 & & \\
\hline Education & & & & 5523 & 214 \\
\hline 7-9 years & 1.42 & $.99-2.00$ & .052 & & \\
\hline $10-12$ years & Ref & & & & \\
\hline$>12$ years & 1.18 & $.86-1.63$ & .294 & & \\
\hline Physical activity & & & & 5539 & 216 \\
\hline Very low & 2.27 & $.92-5.59$ & .075 & & \\
\hline Low & 1.56 & $.88-2.74$ & .125 & & \\
\hline Middle & Ref & & & & \\
\hline Middle-high & 1.02 & $.76-1.35$ & .914 & & \\
\hline High & .76 & $.33-1.73$ & .508 & & \\
\hline Very high & $6.34 \mathrm{E}-16$ & 0 & 1.000 & & \\
\hline Activity high/low & 1.70 & $1.07-2.74$ & .026 & 5539 & 216 \\
\hline Current smoker & 1.43 & $1.04-1.96$ & .028 & 5533 & 216 \\
\hline $\begin{array}{l}\text { Former smoker } \\
\text { (Ref non-smoker) }\end{array}$ & .92 & $.65-1.32$ & .656 & & \\
\hline Height & 1.03 & $1.00-1.06$ & .013 & 5482 & 213 \\
\hline Waist circumference & 1.03 & $1.02-1.04$ & 0 & 5041 & 198 \\
\hline Alcohol & & & & 5398 & 211 \\
\hline $0 \mathrm{~g} / \mathrm{w}$ & 1.26 & $.93-1.70$ & .135 & & \\
\hline $0-12 \mathrm{~g} / \mathrm{w}$ & Ref & & & & \\
\hline$>12 \mathrm{~g} / \mathrm{w}<130 \mathrm{~g} / \mathrm{w}$ & .77 & $.48-1.22$ & .265 & & \\
\hline Sugar & & & & 5580 & 216 \\
\hline Daily & 1.70 & $.97-3.01$ & .066 & & \\
\hline Sometimes & Ref & & & & \\
\hline Avoids & 1.05 & $.78-1.42$ & .748 & & \\
\hline Fat in food & & & & 5353 & 205 \\
\hline Much & 1.46 & $.89-2.40$ & .132 & & \\
\hline Careful with & Ref & & & & \\
\hline Avoids & 1.11 & $.82-1.49$ & .509 & & \\
\hline Fiber & & & & 5547 & 215 \\
\hline Low intake & 1.16 & $.42-3.13$ & .771 & & \\
\hline Regularly & Ref & & & & \\
\hline Much & .77 & $.58-1.03$ & .078 & & \\
\hline Fruit & & & & 5594 & 219 \\
\hline Rarely & 1 & $.76-1.32$ & .985 & & \\
\hline Regularly & Ref & & & & \\
\hline Much & .76 & $.24-2.41$ & .644 & & \\
\hline Portion size & & & & 5240 & 198 \\
\hline Big & .81 & $.45-1.46$ & .481 & & \\
\hline Regular & Ref & & & & \\
\hline Small & .95 & $.70-1.30$ & .753 & & \\
\hline Diet & 1.38 & $.94-2.00$ & .095 & 5612 & 220 \\
\hline Family history & & & & 5477 & 216 \\
\hline Yes & 1.38 & $.93-2.06$ & .112 & & \\
\hline No & Ref & & & & \\
\hline
\end{tabular}


Table 3 (continued)

\begin{tabular}{llllll}
\hline & Hazard ratio & $95 \% \mathrm{CI}$ & $\mathrm{p}$ & $\mathrm{n}$ & Failures \\
\hline Don't know & 1.11 & $.68-1.83$ & .675 & & \\
Acetylsalicylic & 1.52 & $.38-6.12$ & .554 & 5626 & 221 \\
Diabetes & .62 & $.28-1.41$ & .261 & 5577 & 221 \\
Hypertension & 1.17 & $.67-2.05$ & .581 & 5626 & 220 \\
Varicose veins & 2.7 & $1.47-4.95$ & .001 & 5626 & 220 \\
Self-rated health & & & & 5529 & 216 \\
1. Very poor & 2.78 & $.99-7.80$ & .051 & & \\
2. & .71 & $.25-1.99$ & .516 & & \\
3. & 1.15 & $.66-2.01$ & .628 & & \\
4. & Ref & & & & \\
5. & .83 & $.55-1.25$ & .374 & & \\
6. & .7 & $.47-1.05$ & .087 & & \\
7. Excellent & .54 & $.34-.85$ & .008 & & \\
Poor self-rated health & 1.51 & $1.13-2.03$ & .005 & 5529 & 216 \\
\hline
\end{tabular}

Self-rated health was dichotomized into the variable Poor self-rated health, with group 1-4 as poor selfrated health and 5-7 as good self-rated health

group and this was even more obvious when categorizing into poor or good SRH.

An unadjusted Cox regression analysis was conducted (Table 3) with the aim to investigate if there were any significant associations between the variables that fell out with significance in the former analysis and incident VTE.

Despite a relatively small difference in mean age between the groups at baseline, there was an increased risk for incident VTE for every year older at baseline (HR 1.05, 95\% CI $1.00-1.10, p=0.033$ ). Cox regression analysis of SRH did not show any significant association with VTE-risk except for a decreased risk for those who rated their health as excellent (HR 0.54, CI 0.34-0.85, p=0.008). When dichotomizing SRH into poor and good respectively, there was an increased risk for those who rated their health as poor (hazard ratio 1.51, CI 1.13-2.03, $\mathrm{p}=0.005$ ). When we dichotomized the variable physical activity, there was an increased incident VTE-risk for the low group (HR 1.70, CI $1.07-2.74, p=0.026)$. Smoking at baseline was associated with a $43 \%$ increased risk of incident VTE (HR 1.43, CI 1.04-1.96, $\mathrm{p}=0.028)$, smokers who had quit smoking at least one month before inclusion had a non-significant decreased risk of incident VTE $(0.92,0.65-1.32, \mathrm{p}=656)$. Waist circumference and varicose veins were associated with an increased risk as well (HR 1.03, CI 1.02-1.04, p $=0.000$ and HR 2.70, CI 2.47 $-4.95, \mathrm{p}=0.001$ respectively). Knowledge about family history of VTE (parents or siblings) was not associated with increased incident VTE-risk (HR 1.38, CI $0.93-2.06, p=0.112$ ). There was a non-significant trend towards an association between unhealthy diet and risk of incident VTE (HR 1.38, CI 0.44-2.00, $\mathrm{p}=0.095$ ). There was no significant association between hypertension before baseline and incident VTE (HR1.17, CI. 0.67-2.05, $\mathrm{p}=0.581$ ).
When the Cox regression results were adjusted for age (Table 4), model 1 showed a 51\% increased risk for incident VTE if SRH was poor (HR 1.51, CI 1.12-2.02 $\mathrm{p}=0.006$ ). When we adjusted for lifestyle-related variables; physical activity, smoking, former smoking and waist circumference in model 2, the association between poor SRH and increased risk of incident VTE decreased to $16 \%$ and was not significant (HR 1.16, CI 0.84-1.61 p=0.370). Even if low physical activity was associated with a significantly increased risk of incident VTE in the unadjusted model, this association was reduced and not significant when adjusting for other variables (HR 1.19, CI 0.62-2.04, p=0.526). In model 3, adjusting for varicose veins and hypertension, the association between SRH and risk of incident VTE increased to $18 \%$ (HR 1.18, CI 0.85-1.65 p=0.315). Even though the increased risk of age remained, it was not statistically significant in any of the models. In model 3, only the wellknown risk factors had significant effect; smoking (HR 1.44, CI $1.02-2.03, \mathrm{p}=0.037$ ), waist circumference (HR 1.03, CI 1.02-1.04, $\mathrm{p}=0.000)$ and varicose veins (HR $2.60 \mathrm{CI}$ $1.40-4.80, \mathrm{p}=0.002)$. When testing the proportional hazards assumptions for model 1 , the global test was significant $(\mathrm{p}=0.0390)$, which means that the hazards were not proportional over time. The second and third model showed proportional hazards $(\mathrm{p}=0.1290, \mathrm{p}=0.1872)$ in the global test.

\section{Discussion}

This is, to our knowledge, the first study that examines SRH as a predictor of incident VTE among middle-aged women in a well-defined cohort. In the multivariate model 3, there was a tendency towards an association between poor SRH and risk 
Table 4 Multivariate Cox regression with the confounding variables that showed a significantly increased incident VTE-risk in the univariate test (Table 3)

\begin{tabular}{|c|c|c|c|}
\hline Total (n) & 5529 & 4806 & 4806 \\
\hline Failures (n) & 216 & 188 & 188 \\
\hline Self-rated health (poor/good) & 1.51 & 1.16 & 1.18 \\
\hline $\mathrm{CI}$ & $1.12-2.02$ & $.84-1.61$ & $.85-1.65$ \\
\hline $\mathrm{p}$ & .006 & .37 & .315 \\
\hline Age & 1.05 & 1.03 & 1.03 \\
\hline $\mathrm{CI}$ & $1.00-1.09$ & $.98-1.08$ & $.98-1.08$ \\
\hline $\mathrm{p}$ & .048 & .193 & .200 \\
\hline Physical activity (low/high) & & 1.19 & .88 \\
\hline CI & & $.69-2.04$ & $.65-1.19$ \\
\hline $\mathrm{p}$ & & .526 & .421 \\
\hline Current smoker* & & 1.44 & 1.44 \\
\hline CI & & $1.02-2.03$ & $1.02-2.03$ \\
\hline $\mathrm{p}$ & & .037 & .037 \\
\hline Former smoker* & & .89 & .90 \\
\hline $\mathrm{CI}$ & & $.61-1.30$ & $.62-1.32$ \\
\hline $\mathrm{p}$ & & .549 & .588 \\
\hline Waist circumference & & 1.03 & 1.03 \\
\hline $\mathrm{CI}$ & & $1.02-1.04$ & $1.02-1.04$ \\
\hline $\mathrm{p}$ & & 0 & 0 \\
\hline Varicose veins (yes/no) & & & 2.6 \\
\hline $\mathrm{CI}$ & & & $1.40-4.80$ \\
\hline $\mathrm{p}$ & & & .002 \\
\hline Hypertension (yes/no) & & & 1.12 \\
\hline $\mathrm{CI}$ & & & $.63-1.98$ \\
\hline $\mathrm{p}$ & & & .696 \\
\hline $\begin{array}{l}\text { Proportional hazard assumption } \\
\text { test }\end{array}$ & 0.039 & 0.1290 & 0.1872 \\
\hline
\end{tabular}

1 st model adjusted by age and SRH. 2nd model adjusted by model 1 , dichotomized level of physical activity, smoking former smoker and waist circumference. Third model is adjusted by model 2, varicose veins and hypertension

*Reference is non-smoker

of incident VTE, but it was not statistically significant. Our results confirmed, however, an association with the already known risk factors varicose veins, smoking and waist circumference $[4,11,12,34]$.

Braekkan et al. suggested that good SRH could attenuate the risk of VTE among people with a permanent workrelated disability. They discussed the possibility that poor SRH may be affected by other diseases that in turn may increase the risk of VTE [31]. If poor SRH was a good predictor of incident VTE, we ought to have observed a significant association in this cohort comprising only women. However, we did not observe any significant association. The reason for this assumption is that SRH has been suggested to be better at predicting different diseases in women than in men [29]. What is notable, however, is that when we excluded those who got affected with VTE between baseline and 5 years follow up, the risk for VTE among those with poor SRH was increased even in the fully adjusted model (HR 1.38, CI 0.96-1.99, $\mathrm{p}=0.086$ ). This shows that there may be a significant association during long time follow-up, but we were unable to capture it in this study. Regarding the association between varicose veins and VTE, Chang et al. [15] pointed out, that it is unknown whether this association is causal or represents a common set of risk factors. Considering the strong association, it can be argued for the need of preventive actions in people with varicose veins. This is especially pertinent since about $40 \%$ of adults are affected by varicose veins, and even a higher share among those who are obese and women with more than two pregnancies [37].

Low physical activity, i.e. less than 30 min vigorous activity 5 days a week [33], was significantly associated with increased risk of incident VTE in the unadjusted model, but not in the multivariate model 3 (Table 4). This may have been due to lack of power. There were no significant associations between self-reported intake of healthy or unhealthy food, alcohol, portion size and risk of incident VTE, which is consistent with previous studies among women, even if there have been suggested associations between unhealthy food, activity level and overweight/obesity [38, 39]. We neither noticed any significant associations between hypertension and risk for VTE, or differences between those who got affected with incident VTE and those who did not, regarding hypertension. Healthy food and a proper amount of physical activity do not seem to prevent VTE, but a healthy way of living may help to prevent a large waist circumference, which turned out to be associated with incident VTE in our study.

Why SRH is associated with arterial CVDs [24] but not with VTE in the present study may have several explanations. It is possible that the study participants changed their way of living after baseline measurements including questionnaires if they became more aware of their negative habits and changed them [40, 41]. Another explanation could be that many risk factors are different between VTE and arterial diseases [7], although some risk factors are shared. It is thus possible that SRH is a risk factor for arterial diseases but not for VTE. SRH may also be a weak risk factor for VTE and that a larger study might find a significant association with SRH, albeit weaker than for arterial disease. Finally, it is possible that $\mathrm{SRH}$ does not represent an additional risk factor for VTE once the other risk factors have been taken into account.

\section{Strengths}

This study is comprised of a well-defined cohort and it contained both self-reported and anthropometric values combined with information from registers. We censored participants who were affected by cancer or any cardiovascular 
disease before the first VTE occurrence during follow-up and diagnosed hypertension and varicose veins after baseline in order to decrease the risk of influences on VTE-risk and poor SRH.

\section{Limitations}

A limitation is that SRH was only measured at baseline as SRH may change over time. However, a study by SargentCox et al. reported that SRH in women remained relatively stable compared with increasing age, whereas men's ratings tended to become more negative [42]. The study was performed in middle-aged women living in a certain area, which limits the generalizability to a wider context, e.g. to men and women in other ages than those enrolled. Due to a limited number of VTE events, we could not compare the occurrence of the different VTE-forms deep vein thrombosis (DVT) and pulmonary embolism (PE) between the groups. For the same reason, we could not perform any sub-analysis with provoked and unprovoked VTE.

\section{Conclusions}

Poor self-rated health does not seem to be useful as a predictor of VTE. Lifestyle associated behaviors such as diet, alcohol consumption and physical activity or hypertension do not seem to have any strong effect on risk of incident VTE either. On the other hand, we could confirm the effect of already known risk factors; varicose veins, smoking and waist circumference. Varicose veins showed a strong association with risk of incident VTE, which suggests that it may be important to work preventively in people with varicose veins, for prevention of future VTE or other complications.

Acknowledgements Open access funding provided by Lund University. The authors wish to thank the Center for Primary Healthcare Research (CPF) statistician Karolina Palmér for the statistical guidance and data management, and science editor Patrick Reilly for his useful comments on the text.

Author contributions PN: Collaborating with study design, statistical analysis, writing the paper. ES: Writing and editing the paper. SC: Writing and editing the paper. JS: Writing and editing the paper. KS: Writing and editing the paper. BZ: Study design, writing and editing paper.

Funding This work was supported by grants awarded to Dr Bengt Zöller by the Swedish Heart-Lung Foundation, ALF funding from Region Skåne awarded to Dr Bengt Zöller and grants awarded to Dr Bengt Zöller by the Swedish Research Council. ALF funding from Region Skåne awarded to Susanna Calling. The funders had no role in the study design; in the collection, analysis, and interpretation of data; in the writing of the report; and in the decision to submit the article for publication.

\section{Compliance with ethical standards}

Conflict of interest The authors declare that they have no conflict of interest.

Ethical approval The WHILA study was approved by the Regional Ethics Committee at Lund University (LU 174-95) and the Data Registry Inspection in Stockholm. Informed consent was obtained from all participants.

Open Access This article is distributed under the terms of the Creative Commons Attribution 4.0 International License (http://creativeco mmons.org/licenses/by/4.0/), which permits unrestricted use, distribution, and reproduction in any medium, provided you give appropriate credit to the original author(s) and the source, provide a link to the Creative Commons license, and indicate if changes were made.

\section{References}

1. Heit JA, Silverstein MD, Mohr DN, Petterson TM, Lohse CM, O'Fallon WM, Melton LJ 3rd (2001) The epidemiology of venous thromboembolism in the community. Thromb Haemost $86: 452-463$

2. Flinterman LE, van Hylckama Vlieg A, Cannegieter SC, Rosendaal FR (2012) Long-term survival in a large cohort of patients with venous thrombosis: incidence and predictors. PLoS Med 9:e1001155

3. Anderson FA, Spencer FA (2003) Risk factors for venous thromboembolism. Circulation 107:I9-I16

4. Holst AG, Jensen G, Prescott E (2010) Risk factors for venous thromboembolism. Circulation 121:1896-1903

5. Chiuve SE, Cook NR, Shay CM, Rexrode KM, Albert CM, Manson JE, Willett WC, Rimm EB (2014) Lifestyle-based prediction model for the prevention of CVD: the Healthy Heart Score. J Am Heart Assoc 3:e00054

6. Prandoni $\mathrm{P}$ (2017) Venous and arterial thrombosis: is there a link? Adv Exp Med Biol 906:273-283

7. Gregson J, Kaptoge S, Bolton T, Pennells L, Willeit P, Burgess S, Bell S, Sweeting M, Rimm EB, Kabrhel C et al (2019) Cardiovascular risk factors associated with venous thromboembolism. JAMA Cardiol 4:163-173

8. Lippi G, Mattiuzzi C, Franchini M (2015) Sleep apnea and venous thromboembolism. Thromb Haemost 114:958-963

9. Deflandre E, Degey S, Opsomer N, Brichant J-F, Joris J (2016) Obstructive sleep apnea and smoking as a risk factor for venous thromboembolism events: review of the literature on the common pathophysiological mechanisms. Obes Surg 26(3):640-648

10. Somers VK, White DP, Amin R, Abraham WT, Costa F, Culebras A, Daniels S, Floras JS, Hunt CE, Olson LJ et al (2008) Sleep apnea and cardiovascular disease. Circulation 118(10):1080-1111

11. Zoller B, Ji J, Sundquist J, Sundquist K (2017) Body height and incident risk of venous thromboembolism: a cosibling design. Circ Cardiovasc Genet 10(5):e001651

12. Ahti TM, Mäkivaara LA, Luukkaala T, Hakama M, Laurikka JO (2010) Lifestyle factors and varicose veins: does cross-sectional design result in underestimate of the risk? Phlebology 25(4):201-206

13. Muller-Buhl U, Leutgeb R, Engeser P, Achankeng EN, Szecsenyi J, Laux G (2012) Varicose veins are a risk factor for deep venous thrombosis in general practice patients. VASA Zeitschrift fur Gefasskrankheiten 41(5):360-365

14. Tiwari A, Lester W, Tang TY (2018) Varicose veins and deep venous thrombosis. JAMA 320(5):509-510 
15. Chang SL, Huang YL, Lee MC, Hu S, Hsiao YC, Chang SW, Chang CJ, Chen PC (2018) Association of varicose veins with incident venous thromboembolism and peripheral artery disease. JAMA 319(8):807-817

16. Zoller B, Ji J, Sundquist J, Sundquist K (2014) Venous thromboembolism and varicose veins share familial susceptibility: a nationwide family study in Sweden. J Am Heart Assoc 3(4): $\mathrm{e} 000850$

17. Zoller B, Ohlsson H, Sundquist J, Sundquist K (2013) Familial risk of venous thromboembolism in first-, second- and thirddegree relatives: a nationwide family study in Sweden. Thromb Haemost 109(3):458-463

18. Zoller B, Li X, Ohlsson H, Ji J, Sundquist J, Sundquist K (2015) Family history of venous thromboembolism as a risk factor and genetic research tool. Thromb Haemost 114(5):890-900

19. Roach REJ, Cannegieter SC, Lijfering WM (2014) Differential risks in men and women for first and recurrent venous thrombosis: the role of genes and environment. J Thromb Haemost 12(10):1593-1600

20. Zöller B, Li X, Sundquist J, Sundquist K (2011) Age- and genderspecific familial risks for venous thromboembolism. Circulation 124(9):1012-1020

21. Christian LM, Glaser R, Porter K, Malarkey WB, Beversdorf D, Kiecolt-Glaser JK (2011) Poorer self-rated health is associated with elevated inflammatory markers among older adults. Psychoneuroendocrinology 36(10):1495-1504

22. Badawi G, Page V, Smith KJ, Gariepy G, Malla A, Wang J, Boyer R, Strychar I, Lesage A, Schmitz N (2013) Self-rated health: a predictor for the three year incidence of major depression in individuals with Type II diabetes. J Affect Disord 145(1):100-105

23. Emmelin M, Weinehall L, Stegmayr B, Dahlgren L, Stenlund H, Wall S (2003) Self-rated ill-health strengthens the effect of biomedical risk factors in predicting stroke, especially for men-an incident case referent study. J Hypertens 21(5):887-896

24. van der Linde RM, Mavaddat N, Luben R, Brayne C, Simmons RK, Khaw KT, Kinmonth AL (2013) Self-rated health and cardiovascular disease incidence: results from a longitudinal populationbased cohort in Norfolk, UK. PLoS ONE 8(6):e65290-e65290

25. Naess S, Eriksen J, Midthjell K, Tambs K (2005) Subjective wellbeing before and after the onset of diabetes mellitus: results of the Nord-Trondelag Health Study. J Diabetes Complicat 19(2):88-95

26. Riise HK, Riise T, Natvig GK, Daltveit AK (2014) Poor self-rated health associated with an increased risk of subsequent development of lung cancer. Quality of life research : an international journal of quality of life aspects of treatment, care and rehabilitation 23(1):145-153

27. Sundquist J, Johansson SE (1997) Self reported poor health and low educational level predictors for mortality: a population based follow up study of 39,156 people in Sweden. J Epidemiol Community Health 51(1):35-40

28. DeSalvo KB, Fan VS, McDonell MB, Fihn SD (2005) Predicting mortality and healthcare utilization with a single question. Health Serv Res 40(4):1234-1246
29. Baćak V, Ólafsdóttir S (2017) Gender and validity of self-rated health in nineteen European countries. Scand J Public Health 45(6):647-653

30. Benyamini Y (2011) Why does self-rated health predict mortality? An update on current knowledge and a research agenda for psychologists. Psychol Health 26(11):1407-1413

31. Braekkan SK, Grosse SD, Okoroh EM, Tsai J, Cannegieter SC, Naess IA, Krokstad S, Hansen JB, Skjeldestad FE (2016) Venous thromboembolism and subsequent permanent work-related disability. J Thromb Haemost 14(10):1978-1987

32. Samsioe G, Lidfeldt J, Nerbrand C, Nilsson P (2010) The women's health in the Lund area (WHILA) study - an overview. Maturitas 65(1):37-45

33. World Health Organization (2011) Global recommendations on physical activity for health. World Health Organization, Geneva

34. Borch KH, Braekkan SK, Mathiesen EB, Njolstad I, Wilsgaard T, Stormer J, Hansen JB (2010) Anthropometric measures of obesity and risk of venous thromboembolism: the Tromso study. Arterioscler Thromb Vasc Biol 30(1):121-127

35. Kirkwood BR, Sterne JAC, Kirkwood BR (2003) Essential medical statistics, 2nd edn. Blackwell Science, Malden

36. Juul S, Frydenberg M (2014) An introduction to Stata for health researchers, 4th edn. Stata Press, College Station

37. Tisi PV (2011) Varicose veins. BMJ Clin Evid 2011:0212

38. Schlesinger S, Neuenschwander M, Schwedhelm C, Hoffmann G, Bechthold A, Boeing H, Schwingshackl L (2019) Food groups and risk of overweight, obesity, and weight gain: a systematic review and dose-response meta-analysis of prospective studies. Adv Nutr 10(2):205-218

39. Kahlmeier S, Wijnhoven TM, Alpiger P, Schweizer C, Breda J, Martin BW (2015) National physical activity recommendations: systematic overview and analysis of the situation in European countries. BMC Public Health 15:133

40. Farnkvist L, Olofsson N, Weinehall L (2008) Did a health dialogue matter? Self-reported cardiovascular disease and diabetes 11 years after health screening. Scand J Prim Health Care 26:135-139

41. Lingfors H, Lindstrom K, Persson LG, Bengtsson C, Lissner L (2003) Lifestyle changes after a health dialogue. Results from the live for life health promotion programme. Scand J Prim Health Care 21:248-252

42. Sargent-Cox KA, Anstey KJ, Luszcz MA (2010) Patterns of longitudinal change in older adults' self-rated health: the effect of the point of reference. Health Psychol 29:143-152

Publisher's Note Springer Nature remains neutral with regard to jurisdictional claims in published maps and institutional affiliations. 